ORNL/TM-2015/466

\title{
Q-Sync Motors in Commercial Refrigeration: Preliminary Test Results and Projected Benefits
}

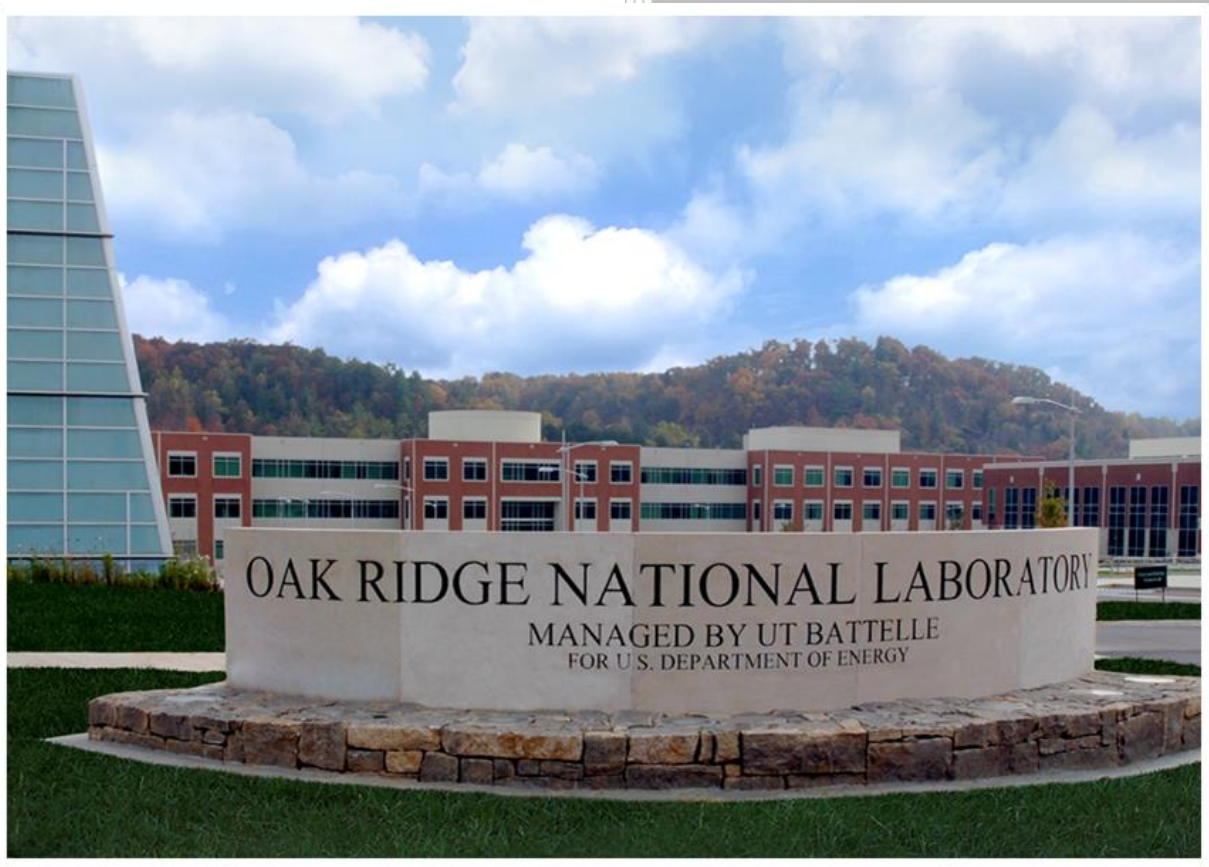

Approved for public release. Distribution is unlimited.

Brian A. Fricke Bryan R. Becker

September 2015 


\section{DOCUMENT AVAILABILITY}

Reports produced after January 1, 1996, are generally available free via US Department of Energy (DOE) SciTech Connect.

Website http://www.osti.gov/scitech/

Reports produced before January 1, 1996, may be purchased by members of the public from the following source:

National Technical Information Service

5285 Port Royal Road

Springfield, VA 22161

Telephone 703-605-6000 (1-800-553-6847)

TDD 703-487-4639

Fax 703-605-6900

E-mail info@ntis.gov

Website http://www.ntis.gov/help/ordermethods.aspx

Reports are available to DOE employees, DOE contractors, Energy Technology Data Exchange representatives, and International Nuclear Information System representatives from the following source:

Office of Scientific and Technical Information

PO Box 62

Oak Ridge, TN 37831

Telephone 865-576-8401

Fax 865-576-5728

E-mail reports@osti.gov

Website http://www.osti.gov/contact.html

This report was prepared as an account of work sponsored by an agency of the United States Government. Neither the United States Government nor any agency thereof, nor any of their employees, makes any warranty, express or implied, or assumes any legal liability or responsibility for the accuracy, completeness, or usefulness of any information, apparatus, product, or process disclosed, or represents that its use would not infringe privately owned rights. Reference herein to any specific commercial product, process, or service by trade name, trademark, manufacturer, or otherwise, does not necessarily constitute or imply its endorsement, recommendation, or favoring by the United States Government or any agency thereof. The views and opinions of authors expressed herein do not necessarily state or reflect those of the United States Government or any agency thereof. 
Building Technologies Research and Integration Center

\title{
Q-SYNC MOTORS IN COMMERCIAL REFRIGERATION: PRELIMINARY TEST RESULTS AND PROJECTED BENEFITS
}

\author{
Brian A. Fricke \\ Bryan R. Becker*
}

Date Published: September 2015

\author{
Prepared by \\ OAK RIDGE NATIONAL LABORATORY \\ Oak Ridge, Tennessee 37831-6283 \\ managed by \\ UT-BATTELLE, LLC \\ for the \\ US DEPARTMENT OF ENERGY \\ under contract DE-AC05-00OR22725
}

\footnotetext{
* University of Missouri - Kansas City, 5100 Rockhill Road, Kansas City, MO 64110-2499
} 



\section{CONTENTS}

Page

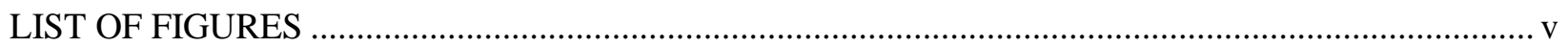

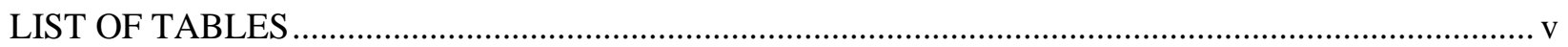

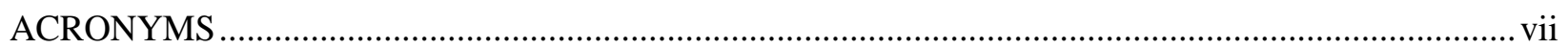

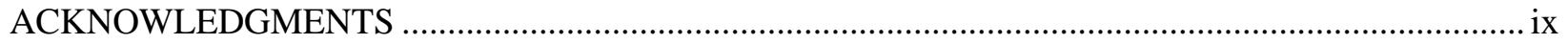

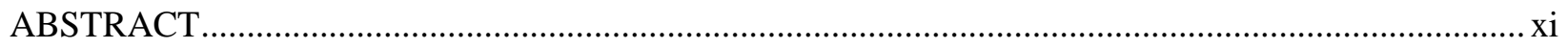

1. INTRODUCTION: EXISTING 9-12 WATT EVAPORATOR FAN MOTOR

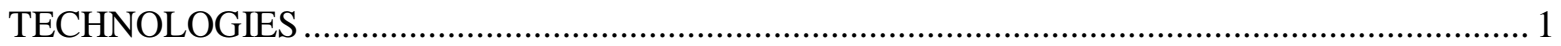

2. THE NEW Q-SYNC MOTOR TECHNOLOGY ….................................................................... 3

3. EVAPORATOR FAN MOTOR FIELD DEMONSTRATION AND PRELIMINARY

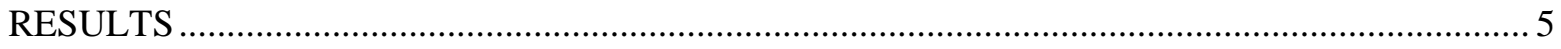

4. POTENTIAL SITE AND SOURCE ENERGY SAVINGS …..................................................... 7

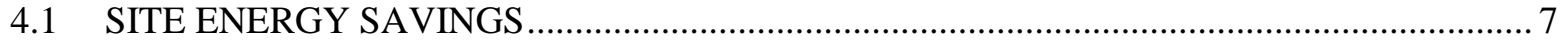

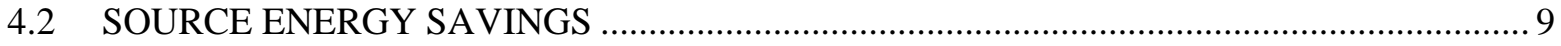

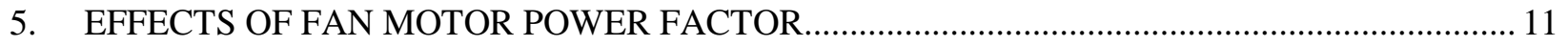

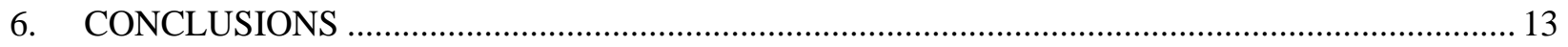

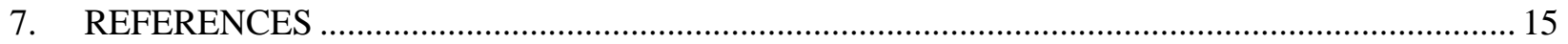





\section{LIST OF FIGURES}

Figure

Figure 1. Performance of EC and Q-Sync fan motors before and after retrofit: (a) current, (b) power........ 5

\section{LIST OF TABLES}

Table

Page

Table 1. Characteristics of evaporator fan motors ............................................................................ 7

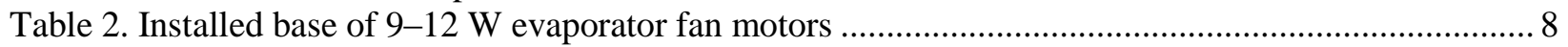

Table 3. Baseline distribution of evaporator fan motors and total site energy consumption ....................... 9

Table 4. Annual source energy consumption and savings for baseline and Q-Sync fan motors ................ 10

Table 5. Annual source energy consumption of fans in residential and commercial buildings................. 14 



\section{ACRONYMS}

AC alternating current

BTO Building Technologies Office, US Department of Energy

DC direct current

DOE US Department of Energy

EC electronically commutatedr

$\mathrm{M} \& \mathrm{~V} \quad$ measurement and verification

NCI Navigant Consulting Inc.

ORNL Oak Ridge National Laboratory

PNNL Pacific Northwest National Laboratory

PSC permanent split capacitor 



\section{ACKNOWLEDGMENTS}

This report and the work described were sponsored by the Commercial Buildings Integration program within the Building Technologies Office of the US Department of Energy Office of Energy Efficiency and Renewable Energy. The authors wish to acknowledge the contributions of Amy Jiron and Charles Llenza in guiding this work and the insightful review comments of Vishaldeep Sharma of ORNL. This work would not have been possible without the excellent support of lab technicians Geoffrey Ormston, Randy Linkous, and Tony Gehl. 



\begin{abstract}
The US Department of Energy Building Technologies Office (DOE BTO) estimates that the commercial sector uses approximately $18 \%$ of all primary or source energy consumed in the United States, or 17.3 quadrillion Btu (quads) (1 quad = 10 $0^{15}$ Btu) (NCI 2013). "Primary" or "source" energy refers to the sum of the energy consumed at the site (site energy) plus the energy required to extract, convert, and transmit that energy to the site, and "site" energy refers to the energy directly consumed at the site, typically measured with utility meters (Deru and Torcellini 2007). The DOE estimates that the conversion from site to source electric energy is 3.16 units of source energy per unit of site energy ( DOE 2011). Therefore, the 17.3 quads of primary energy consumed by the US commercial sector equates to approximately $5.07 \times 10^{12}$ kilowatt hours $(\mathrm{kWh})$ of primary energy $\left(1 \mathrm{Btu}=2.931 \times 10^{-4} \mathrm{kWh}\right)$, which in turn converts to $1.60 \times 10^{12} \mathrm{kWh}$ of site energy, valued at approximately $\$ 170$ billion (EIA 2015) ${ }^{2}$.

Of that 17.3 quads of primary energy, DOE BTO estimates that the primary energy consumption of electric motor-driven systems in the commercial sector is 4.87 quads and that the motors in central commercial refrigeration and beverage vending machines account for $6.7 \%$ and $3.6 \%$ of that 4.87 quads, respectively (NCI 2013). This equates to approximately $96 \times 10^{9} \mathrm{kWh}$ of primary energy for central commercial refrigeration, which in turn converts to $30 \times 10^{9} \mathrm{kWh}$ of site energy, valued at approximately $\$ 3.2$ billion. For beverage vending machines, this equates to $52 \times 10^{9} \mathrm{kWh}$ of primary energy, which in turn converts to $16 \times 10^{9} \mathrm{kWh}$ of site energy, valued at approximately $\$ 1.7$ billion.

Although higher-efficiency motors have been increasingly used in central commercial refrigeration and beverage vending machines, the installed base of smaller 9-12 W evaporator fan motors continues to be dominated by lower-efficiency shaded-pole motors. Over the past 10 years, the higher-efficiency electronically commutated (EC) motor has begun to penetrate the market. While EC motors are significantly more efficient than shaded pole motors, QM Power Inc.'s newly available, UL approved QSync motors offer even greater efficiency at a comparable first cost. In addition to transforming electrical energy into mechanical energy more efficiently than EC motors, Q-Sync motors have much higher power factors, meaning that they accept energy from the grid much more efficiently. The resulting reduced current draw means that the electric utility can reduce the amount of energy that it needs to supply to the grid.

This report provides background information on various fractional-horsepower electric motor technologies, summarizes initial data from a DOE-sponsored Q-Sync motor demonstration project, and extrapolates that data to project the potential economic and environmental benefits resulting from upgrading the current installed base of 9-12 W evaporator fan motors to Q-Sync motors.
\end{abstract}

\footnotetext{
${ }^{2}$ The Energy Information Administration reported that the average commercial electricity rate was 10.58 cents per kilowatt-hour during the first quarter of 2015 (EIA 2015). This price will be used throughout this report in translating kilowatt-hours used/saved to dollars at the motor level.
} 



\section{INTRODUCTION: EXISTING 9-12 WATT EVAPORATOR FAN MOTOR TECHNOLOGIES}

Evaporator fan motors are a fractional horsepower in size, are responsible for moving air across the evaporator coil, and typically run at one speed. The manufacturer will match the motor size and blade to the evaporator coil to meet the expected load on the case under most conditions. Higher-efficiency evaporator fan motors reduce energy consumption by requiring less electrical power to generate the same motor shaft output power (NCI/PNNL 2011).

Historically, shaded-pole motors have been the most commonly used evaporator fan motors in commercial refrigeration equipment and beverage vending machines. The shaded-pole motor, a type of single-phase AC induction motor, is the simplest and least expensive type of fractional-horsepower motor. It is also the least efficient in terms of converting electrical energy into mechanical energy. The 9$12 \mathrm{~W}$ sizes commonly used for evaporator fans in these systems are typically $20 \%$ efficient (NCI/PNNL 2011). Given that motor efficiency losses are released as heat, this inefficiency also increases the refrigeration load, further decreasing overall refrigeration system efficiency.

Electronically commutated (EC) motors, also known as brushless DC motors, were conceived in 1962 (Wilson and Trickey 1962) and first became widely commercialized in the late 1980s, after higher-quality rare-earth permanent magnets became more readily available (de Almeida and Greenberg 2004). The use of these premium-priced EC motors for commercial refrigeration fan applications began in earnest 10 to 15 years ago, and their use has increased because of economic incentives and regulatory requirements. Another motor type, the permanent split capacitor (PSC) motor, which holds a limited share of the market, offers a mid-point between shaded-pole and EC motor price and efficiency levels. The Department of Energy (DOE) reports that for commercial refrigeration evaporator fan motor applications, state-of-the-art EC motors are 66\% efficient and PSC motors are usually about $29 \%$ efficient (NCI/PNNL 2011).

All electric motors function as converters of electrical energy to magnetism and then to mechanical rotating motion. The operation of all electric motors is based on the interaction between a field magnet and a magnetic rotor. The electromagnetic interactions between these two magnets cause the rotor to rotate. The different types of motors result from the manner in which the rotating magnetic fields are generated.

In an induction motor, the AC current is fed into the stator coil, which creates a rotating magnetic field around the stator. This rotating magnetic field in the stator induces a current in the rotor coil, which in turn, generates a magnetic field around the rotor. The magnetic fields of the rotor and stator interact. As the magnetic field in the stator rotates, the rotor follows it and torque is generated.

Single-phase induction motors suffer from a serious shortcoming in that they only produce an interaction of two rotating magnetic fields when the rotor is rotating. Simply powering the electromagnet is not sufficient to start such a motor. One of the most significant differences among various types of single-phase induction motors is the way they handle this start-up problem (NCI/PNNL 2011).

Nearly all inexpensive fan motors are either shaded-pole or PSC induction motors. In a shaded-pole motor, a shading ring, typically a single short-circuited turn of thick copper, surrounds one side of the stator poles. Most of the magnetic flux from the stator crosses the air-gap to the rotor. However, a small portion of the flux passes through the shading ring and induces a current in the ring. The resulting magnetic flux in the ring reaches a peak after the main flux, thereby producing a rotation of the flux across the face of the stator poles. This shift in the flux across the face of the stator poles is required to start the motor. Incidentally, the side of the stator poles where the shading ring is placed dictates the direction of rotation of the motor (Hughes and Drury 2013). Because a portion of the electrical energy input is used to induce the magnetic field of the shading ring, and since the imbalance between the shaded and unshaded portions of the stator poles remains throughout operation, shaded-pole motors are inefficient. 
In a PSC motor, a smaller start-up winding is present in addition to the main stator winding. The startup winding is electrically connected in parallel with the main stator winding and in series with a capacitor, which causes a phase-shift of the current in the two windings. At startup, the interactions between the magnetic field generated by the start-up winding and that generated by the main winding create a rotating magnetic field that induces rotation of the rotor. As the motor reaches steady state, the start-up winding becomes an auxiliary winding, thereby approximating two-phase operation at the rated load point. For that reason, PSC motors are more energy efficient than their shaded-pole counterparts (NCI/PNNL 2011).

The EC motor, also known as the brushless permanent magnet motor, is more energy efficient than either shaded-pole or PSC motors. In the EC motor, the grid-suppled AC current is rectified to DC current. The stator is composed of individual windings. The DC current to these windings is electronically commutated (switched) by digital signals from simple rotor position sensors. As the DC current is switched to the various stator windings, a rotating magnetic field is created. This rotating magnetic field creates a torque by pulling the permanent-magnet rotor. This combination permits the motor to develop a smooth torque, regardless of speed (de Almeida and Greenberg 2004). 


\section{THE NEW Q-SYNC MOTOR TECHNOLOGY}

QM Power Q-Sync motors are designed to be superior to EC motors, as well as shaded-pole and PSC motors. The Q-Sync motor is a permanent magnet synchronous AC motor that can directly use gridsupplied AC current without the need to rectify to DC. Synchronous motors are so named because the rotation of the motor's shaft is synchronized with the frequency of the supplied current. Previously, synchronous motors have been prohibitively expensive for commercial refrigeration evaporator fan applications because of the high cost of the electronic control circuit that is required to bring the synchronous motor up to synchronous speed. However, Q-Sync's novel, patent-pending controller is simpler and lower in cost than previous synchronous motor controllers or EC motor controllers, making the Q-Sync motor a cost-effective alternative in the commercial refrigeration market.

The QM Power Q-Sync motor technology includes a split-wound stator coil as well as a motor controller with a Hall effect sensor to detect rotor position. Upon startup, or when the Hall effect sensor detects that the motor is not running at synchronous speed, the motor controller modifies the frequency of the AC current delivered to the stator coil to bring the motor to synchronous speed. When the frequency detected by the Hall effect sensor matches the frequency of the input AC, the motor is running synchronously. If the motor is running synchronously, the motor controller is not needed and is switched off until either the motor falls out of sync or the motor is stopped and restarted. If the motor slows below synchronous speed, then the motor controller will control the motor timing as it does for startup. Using this method improves overall motor efficiency and the expected lifetime of the components in the circuit (Flynn and Tracy 2014).

As a result, Q-Sync motors use less energy to provide the same power output, compared with EC and shaded-pole or PSC motors. Since the Q-Sync motor is a permanent magnet motor, it requires less current than an induction motor to produce the same power because no magnetizing current is necessary. Furthermore, compared with an EC motor, the Q-Sync motor does not need to rectify AC to DC, thereby eliminating power-consuming electronics. Moreover, because they can use AC power directly from the grid, Q-Sync motors have much higher power factors than EC motors. While the superior power factor does not mean that the motor uses less power on site, it does mean that the utility is able to supply less power to the grid per unit of output of the motor. Another inherent advantage of Q-Sync motors is that the field coils are energized before the electronic controller, thereby protecting the electronics against power surges. Finally, the elimination of the electronics from the circuit while the motor operates at synchronous speed is expected to increase the reliability and service life of Q-Sync motors. 


\section{EVAPORATOR FAN MOTOR FIELD DEMONSTRATION AND PRELIMINARY RESULTS}

QM Power Inc. was recently awarded a DOE grant to support a field demonstration project to quantify the energy savings realized by switching from shaded-pole, PSC, or EC evaporator fan motors to Q-Sync motors. Oak Ridge National Laboratory (ORNL) is responsible for measurement and verification $(\mathrm{M} \& \mathrm{~V})$ in this project. The $\mathrm{M} \& \mathrm{~V}$ plan consists of side-by-side measurement of the power consumption of Q-Sync and shaded-pole, PSC, or EC evaporator fan motors in identical refrigerated display cases. The $\mathrm{M} \& \mathrm{~V}$ plan includes provisions for measuring fan motor power, current, and power factor, as well as display case discharge and return air temperatures and ambient store temperature.

The first such side-by-side comparison has begun in a $16 \mathrm{ft}$ medium-temperature vertical multi-deck refrigerated display case at a Hy-Vee Supermarket located in the Kansas City metropolitan area. Before this side-by-side comparison, the display case contained four $12 \mathrm{~W} \mathrm{EC} \mathrm{evaporator} \mathrm{fan} \mathrm{motors,} \mathrm{two} \mathrm{in} \mathrm{each}$ $8 \mathrm{ft}$ section. At the onset of this comparison, the two existing EC motors in one of the $8 \mathrm{ft}$ sections were replaced with two $12 \mathrm{~W}$ Q-Sync motors. Thus, at this test site, two $12 \mathrm{~W}$ Q-Sync motors are being compared with two existing $12 \mathrm{~W}$ EC motors.

The initial results reveal that the Q-Sync motors offer a significant advantage over the existing EC motors. On average, the Q-Sync power consumption is $27.4 \%$ lower (32.8 versus $45.2 \mathrm{~W}$ ); and the current draw is $53.3 \%$ lower $(0.292$ versus $0.625 \mathrm{~A}$ ). Assuming a total motor output of $24 \mathrm{~W}$ (each display case has two $12 \mathrm{~W}$ fan motors) implies that the Q-Sync motor efficiency is $73.1 \%$ versus the EC motor efficiency of $53.1 \%$. In addition, the power factors are 0.936 for the Q-Sync motors and 0.601 for the EC motors. Graphs depicting the changes in power and current draw before and following the motor retrofit can be seen in Figure 1.

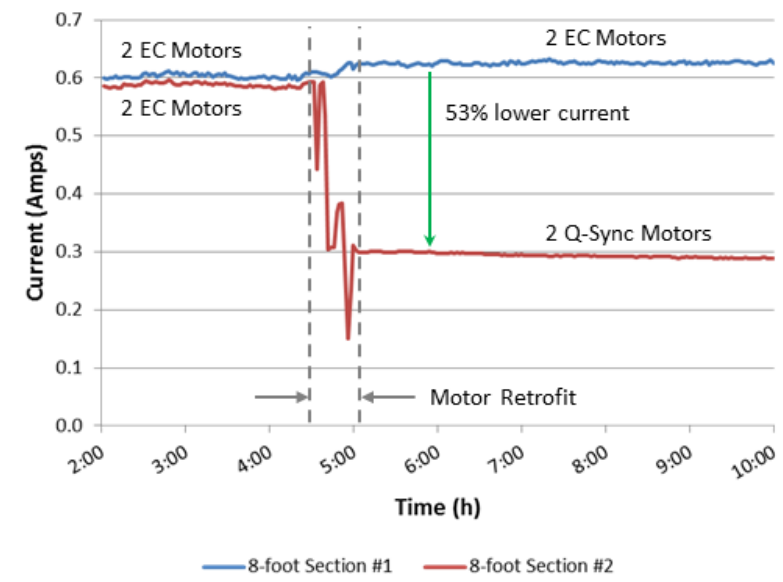

(a)

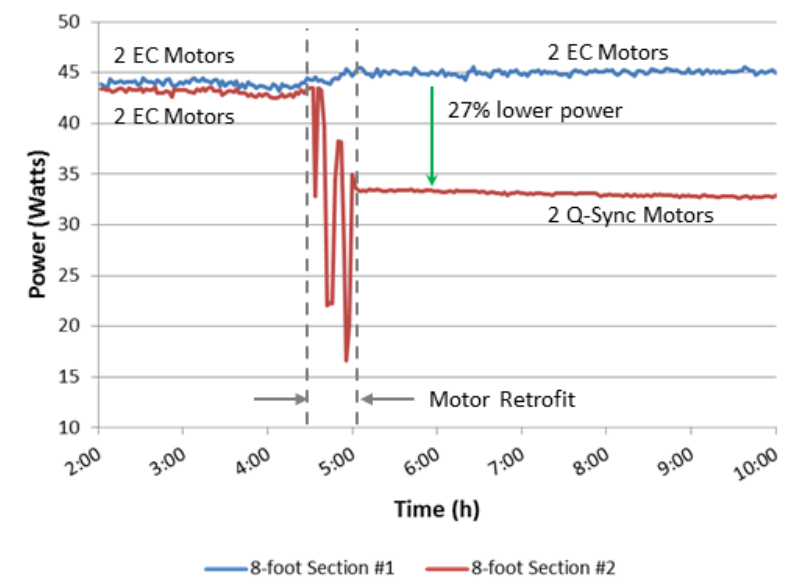

(b)

Figure 1. Performance of EC and Q-Sync fan motors before and after retrofit: (a) current, (b) power. 


\section{POTENTIAL SITE AND SOURCE ENERGY SAVINGS}

Using the preliminary test data discussed above, the potential site and source energy savings associated with retrofitting the existing installed base of 9-12 W commercial refrigeration evaporator fan motors with Q-Sync fan motors can be estimated.

\subsection{SITE ENERGY SAVINGS}

For purposes of comparison, a baseline must be established. This baseline includes performance characteristics for the current installed base of evaporator fan motor types, as well as statistics regarding the installed base of commercial refrigeration evaporator fan motors.

The characteristics of various types of evaporator fan motors are given in Table 1 . The motor efficiencies of shaded-pole and new EC motors were obtained from NCI/PNNL (2011). The motor efficiencies and power factors of the old EC and Q-Sync motors were obtained from the preliminary test data discussed in Section 3. The power factor of shaded-pole motors and new EC motors was assumed to be 0.601 , which is the value measured for the old EC motors discussed in Section 3. Output power for all motors was assumed to be $12 \mathrm{~W}$. For the old EC motors and Q-Sync motors, input power was measured as discussed in Section 3; and for the shaded-pole and the new EC motors, the input power was calculated from the assumed output power and motor efficiency. It was assumed that all evaporator fan motors in commercial refrigeration equipment and beverage vending machines operated continuously for 8760 hours per year.

Table 1. Characteristics of evaporator fan motors

\begin{tabular}{|c|c|c|c|c|}
\hline Motor type & $\begin{array}{c}\text { Motor } \\
\text { efficiency } \\
(\%)\end{array}$ & $\begin{array}{l}\text { Power } \\
\text { factor }\end{array}$ & $\begin{array}{c}\text { Output } \\
\text { power }(W)\end{array}$ & $\begin{array}{c}\text { Input } \\
\text { power }(W)\end{array}$ \\
\hline \multicolumn{5}{|c|}{ Application: Commercial Refrigeration Equipment } \\
\hline Shaded-pole ${ }^{a}$ & 20.0 & 0.601 & 12 & 60.0 \\
\hline EC motor, old ${ }^{b}$ & 53.1 & 0.601 & 12 & 22.6 \\
\hline EC motor, new ${ }^{a}$ & 66.0 & 0.601 & 12 & 18.2 \\
\hline Q-Sync ${ }^{b}$ & 73.1 & 0.936 & 12 & 16.4 \\
\hline \multicolumn{5}{|c|}{ Application: Beverage Vending Machines } \\
\hline Shaded-pole ${ }^{a}$ & 20.0 & 0.601 & 12 & 60.0 \\
\hline EC motor, old ${ }^{b}$ & 53.1 & 0.601 & 12 & 22.6 \\
\hline EC motor, new ${ }^{a}$ & 66.0 & 0.601 & 12 & 18.2 \\
\hline Q-Sync ${ }^{b}$ & 73.1 & 0.936 & 12 & 16.4 \\
\hline
\end{tabular}

${ }^{a}$ Source: NCI/PNNL (2011).

${ }^{b}$ Source: Preliminary test data discussed in Section 3.

Table 2 provides details of the number of installed 9-12 W evaporator fan motors. Based on a survey of the installed base, it is estimated that there are approximately $15.8 \times 10^{6}$ evaporator fan motors installed in commercial refrigeration equipment and beverage vending machines. Facility count information was obtained from Progressive Grocer (2015), the Association for Convenience and Fuel Retailing (NACS 2015), the National Restaurant Association (NRA 2015), IBIS World (2015) and Statistic Brain (2015), and the number of motors per facility was estimated based on discussions with industry partners. 
Table 2. Installed base of 9-12 W evaporator fan motors

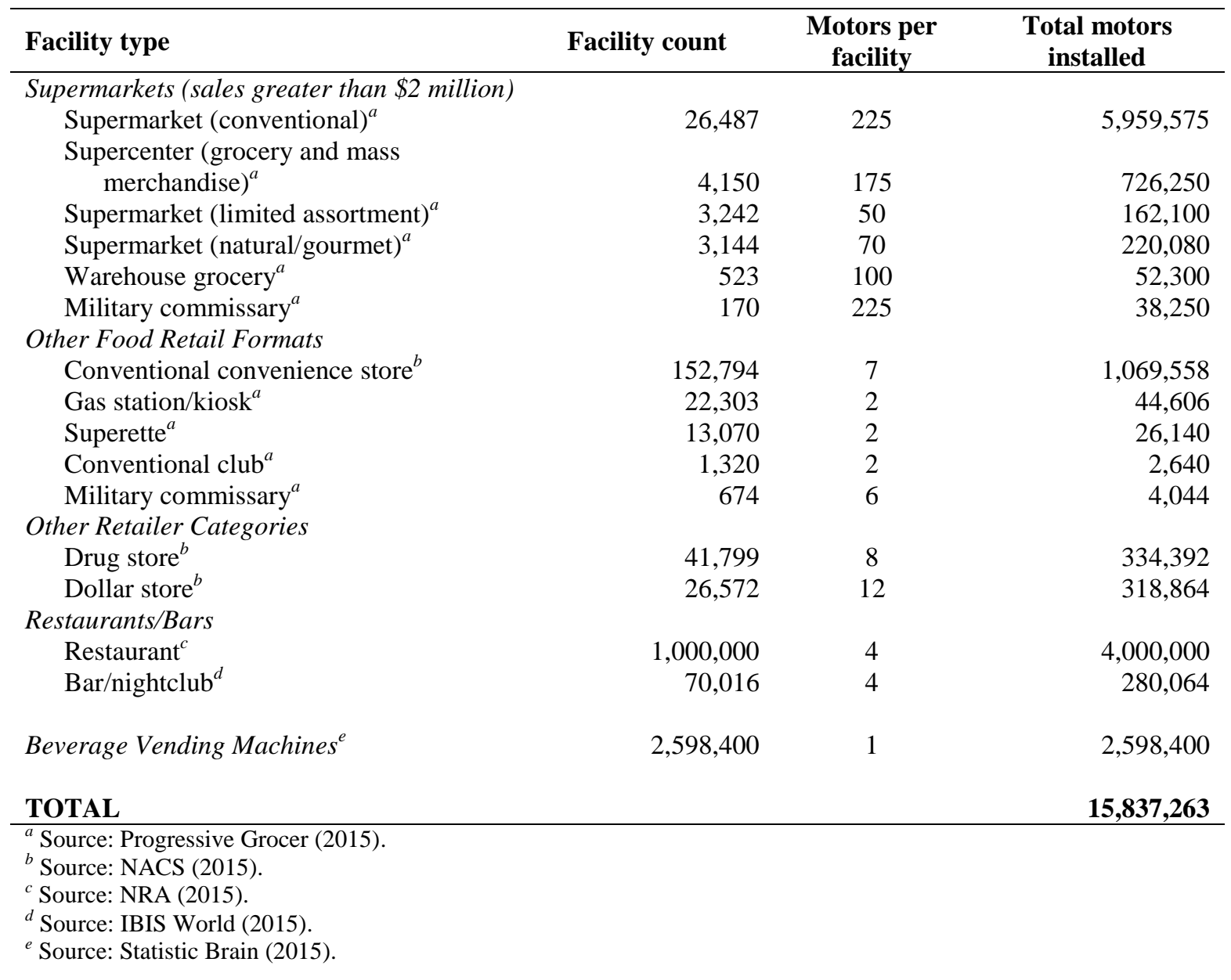

Table 3 shows the assumed distribution of motor types for the existing installed base of evaporator fan motors for each application listed in Table 2. This assumed distribution was estimated based on discussions with industry partners.

Table 3 also shows the total annual site electrical energy consumption of these fan motors. As shown in Table 3 for the baseline case, it is estimated that $7.2 \times 10^{9} \mathrm{kWh}(0.024$ quad $)$ per year of site electricity is consumed by the existing installed base of 9-12 W evaporator fan motors. Assuming the cost of electricity is 10.58 cents per kilowatt-hour (EIA 2015), this translates into $\$ 757$ million. Also, assuming carbon dioxide equivalent emissions of $1.67 \mathrm{lb}$ of $\mathrm{CO}_{2}$ per kilowatt-hour of electricity delivered (Deru and Torcellini 2007), the $\mathrm{CO}_{2}$ emissions associated with the currently installed base of evaporator fan motors is estimated to be $12 \times 10^{9} \mathrm{lb}$. 
Table 3. Baseline distribution of evaporator fan motors and total site energy consumption

\begin{tabular}{|c|c|c|}
\hline $\begin{array}{l}\text { Motor type by } \\
\text { application }\end{array}$ & $\begin{array}{c}\text { Percentage of } \\
\text { installed base } \\
(\%)\end{array}$ & $\begin{array}{c}\text { Annual site } \\
\text { electrical energy } \\
\text { consumption } \\
\text { (kWh/year) } \\
\end{array}$ \\
\hline \multicolumn{3}{|l|}{ Supermarkets } \\
\hline Shaded-pole & 65 & $2,445,648,730$ \\
\hline EC motor, old & 30 & $425,385,699$ \\
\hline EC motor, new & 5 & $57,008,129$ \\
\hline \multicolumn{3}{|c|}{ Other Food Retail Formats } \\
\hline Shaded-pole & 85 & $512,428,359$ \\
\hline EC motor, old & 15 & $34,078,965$ \\
\hline EC motor, new & 0 & \\
\hline \multicolumn{3}{|c|}{ Other Retail Categories } \\
\hline Shaded-pole & 75 & $257,513,515$ \\
\hline EC motor, old & 20 & $25,879,130$ \\
\hline EC motor, new & 5 & $5,202,293$ \\
\hline \multicolumn{3}{|l|}{ Restaurants and Bars } \\
\hline Shaded-pole & 90 & $2,024,641,475$ \\
\hline EC motor, old & 10 & $84,778,656$ \\
\hline EC motor, new & 0 & \\
\hline \multicolumn{3}{|c|}{ Beverage Vending Machines } \\
\hline Shaded-pole & 90 & $1,229,147,136$ \\
\hline EC motor, old & 10 & $51,468,590$ \\
\hline EC motor, new & 0 & \\
\hline TOTAL & & $7,153,180,677$ \\
\hline
\end{tabular}

If all currently installed fan motors were retrofitted with Q-Sync fan motors, the total site electricity consumption would be estimated at $2.3 \times 10^{9} \mathrm{kWh}$ per year. This represents a site energy savings of approximately $68 \%$, or $4.9 \times 10^{9} \mathrm{kWh} /$ year $(0.017$ quad/year), resulting in an annual cost savings of $\$ 516$ million compared with the base case. Furthermore, Q-Sync motors are estimated to reduce the annual $\mathrm{CO}_{2}$ equivalent emissions by approximately $8.1 \times 10^{9} \mathrm{lb}$ compared with the baseline.

\subsection{SOURCE ENERGY SAVINGS}

Based on the site energy analysis presented, the potential source energy savings associated with retrofitting existing 9-12 W commercial refrigeration evaporator fan motors with Q-Sync fan motors can be estimated. Recall that "source energy" refers to the sum of the energy consumed at the site (site energy) plus the energy required to extract, convert, and transmit that energy to the site, whereas "site energy" refers to the energy directly consumed at the site (Deru and Torcellini 2007). Furthermore, DOE estimates that the conversion from site to source electric energy is 3.16 units of source energy per unit of site energy (DOE 2011).

The site and source energy consumption and potential energy savings for the Q-Sync fan motor retrofit scenario discussed are given in Table 4 . This table gives the source energy consumption for the baseline case of installed commercial refrigeration evaporator fan motors, as well as the source energy consumption and savings for a retrofit consisting entirely of Q-Sync fan motors.

The source energy consumption of all electric motors in central commercial refrigeration and beverage vending machines is approximately $147 \times 10^{9} \mathrm{kWh}$ per year, or 0.50 quad per year (NCI 2013). If all currently installed evaporator fan motors were replaced with Q-Sync fan motors, the total source energy attributed to all electric motors in central commercial refrigeration and beverage vending machines could be reduced to 0.45 quad/year, representing a savings of $10 \%$. 
Table 4. Annual source energy consumption and savings for baseline and Q-Sync fan motors

\begin{tabular}{lccc}
\hline Installed base & $\begin{array}{c}\text { Annual site electrical } \\
\text { energy consumption } \\
\text { (kWh/year) }\end{array}$ & $\begin{array}{c}\text { Annual source energy } \\
\text { consumption } \\
\text { (quad/year) }\end{array}$ & $\begin{array}{c}\text { Annual source energy } \\
\text { savings vs. baseline } \\
\text { (quad/year) }\end{array}$ \\
\hline Baseline fan motors & $7.2 \times 10^{9}$ & 0.077 \\
Q-Sync fan motors & $2.3 \times 10^{9}$ & 0.025 & 0.053 \\
\hline
\end{tabular}




\section{EFFECTS OF FAN MOTOR POWER FACTOR}

The analysis presented in Section 4.1 estimates only the "real" energy consumed at the site by the various types of evaporator fan motors. However, given that Q-Sync fan motors exhibit a significantly higher power factor than EC and shaded-pole or PSC motors, it is expected that, through the implementation of Q-Sync motors, utility companies will realize additional "apparent" energy savings at their power plants beyond the "real" energy savings at the sites. This additional apparent energy savings at the power plant should encourage utility companies to offer incentive programs for retrofitting Q-Sync motors in place of EC and shaded-pole or PSC motors.

The "real" power, $P$, consumed by evaporator fan motors - that is, the power that produces useful work - is the power that would be measured at the site by a utility power meter. The analysis presented in Section 4.1 uses this "real" power to determine the total site energy consumption due to operation of evaporator fan motors. However, electric motors also require reactive power, $Q$, to operate. The reactive power does not do any useful work, but it provides the magnetic field required to produce rotation of the motor's rotor. Reactive power is typically not measured at the site; however, the power plant must provide the reactive power, in addition to the real power, for the motor to operate.

In a purely resistive AC circuit, voltage and current are perfectly in phase, and there is no reactive power. All the power consumed by the resistive load is real power. On the other hand, AC circuits with inductors and/or capacitors exhibit a phase difference between the voltage and the current; thus both real and reactive power are required by the load. The vector sum of the real power, $P$, and the reactive power, $Q$, is called the apparent power, $S$. Thus, the power plant must supply this apparent power for the motor to operate. The ratio between real power and apparent power is defined as the power factor, $P F$. Real power, reactive power, apparent power and power factor are related as follows:

$$
\begin{gathered}
S^{2}=P^{2}+Q^{2} \\
P F=\frac{P}{S}=\frac{P}{V_{r m s} I_{r m s}}
\end{gathered}
$$

where $V_{r m s}$ is the root-mean-square voltage and $I_{r m s}$ is the root-mean-square current.

For a resistive load (such as an electric heating element or an incandescent light bulb), the real and apparent power are equal since there is no reactive power; thus the power factor is one. However, for an inductive load (such as an induction motor), both real power and reactive power are required; therefore, real power is less than apparent power and the resulting power factor is less than one.

For the same real power output, a load with a low power factor requires more current than a load with a high power factor. Thus Q-Sync fan motors, with their high power factor, will consume less current than motors with a lower power factor. The lower current draw of the Q-Sync motors means reduced generation and transmission costs for the utility company.

The reduction in apparent power generation at the power plant due to evaporator fan motor retrofits can be estimated using the power factors of the existing 9-12 W commercial refrigeration evaporator fan motors and the Q-Sync fan motors given in Table 1.

As discussed in Section 4.1 and shown in Table 3, for the baseline case of all shaded-pole and EC motors, the total site electricity consumption is estimated to be $7.2 \times 10^{9} \mathrm{kWh}$ per year. Dividing by 8760 hours per year, the instantaneous real power required is $0.82 \times 10^{9} \mathrm{~W}$. As shown in Table 1 , the power factor for the baseline case of all shaded-pole and EC motors is assumed to be 0.601. Dividing the instantaneous real power by this power factor results in an instantaneous apparent power of $1.4 \times 10^{9}$ VA. The current required to supply this instantaneous apparent power can be calculated as follows:

$$
I_{r m s}=\frac{P}{V_{r m s} P F}=\frac{S}{V_{r m s}} .
$$


Assuming $V_{r m s}=120 \mathrm{~V}$, electric utility companies would need to supply $11 \times 10^{6} \mathrm{~A}$ of current to the grid to provide the instantaneous apparent power required by the baseline case of all shaded-pole and EC motors.

In contrast, as discussed in Section 4.1, if all currently installed fan motors were retrofitted with QSync fan motors, the total site electricity consumption would be estimated at $2.3 \times 10^{9} \mathrm{kWh}$ per year. Dividing by 8760 hours per year, the instantaneous real power required would be $0.26 \times 10^{9} \mathrm{~W}$. As shown in Table 1, the power factor for the Q-Sync motor is 0.936 . Dividing the instantaneous real power by this power factor results in an instantaneous apparent power of $0.28 \times 10^{9} \mathrm{VA}$. To provide this instantaneous apparent power required by the Q-Sync motors, electric utility companies would need to supply $2.3 \times 10^{6} \mathrm{~A}$ of current to the grid.

Thus, comparing the baseline case of all shaded-pole and EC motors with an installed base of Q-Sync motors, it can be seen that utilities would be required to supply $80 \%$ less apparent power and $80 \%$ less current for Q-Sync motors compared with the baseline combination of shaded-pole and EC motors. This would amount to significant savings for the utilities. Additional savings could be possible from a reduction in transmission line investments or related maintenance due to the lower levels of delivered current. 


\section{CONCLUSIONS}

In this paper, various existing 9-12 W fan motor technologies were discussed: shaded-pole, PSC, and EC motors. Furthermore, a new synchronous motor technology, the Q- Sync motor developed by QM Power Inc. was discussed.

A field demonstration project was described wherein a side-by-side comparison is being conducted in a $16 \mathrm{ft}$ medium-temperature vertical multi-deck refrigerated display case at a Hy-Vee Supermarket located in the Kansas City metropolitan area. Two $12 \mathrm{~W}$ Q-Sync motors are being compared with two existing $12 \mathrm{~W}$ EC motors. The initial results show that compared with the EC motor, the Q-Sync motor power consumption is $27.4 \%$ lower and the current draw is $53.3 \%$ lower. Thus the Q-Sync motor efficiency is $73.1 \%$ versus $53.1 \%$ for the EC motor. Furthermore, the Q-Sync motor power factor is 0.936 compared with 0.601 for the existing EC motor.

Based on these preliminary test data, potential site and source energy savings associated with retrofitting the existing installed base of 9-12 W commercial refrigeration evaporator fan motors with Q-Sync fan motors was estimated. It was found that retrofitting the installed base with Q-Sync motors would produce a $68 \%$ site energy savings, or $4.9 \times 10^{9} \mathrm{kWh} /$ year $(0.017$ quad/year). This would result in an annual cost savings of $\$ 516$ million and reduce the annual $\mathrm{CO}_{2}$ equivalent emissions by $8.1 \times 10^{9} \mathrm{lb}$. This amounts to a source energy savings of 0.053 quad per year.

Finally, the effects of fan motor power factor were discussed, including the relationship between real, reactive, and apparent power. It was shown that Q-Sync motors, with their high power factors, will consume less current than motors with a lower power factor. Comparing an installed base of Q-Sync versus the baseline case of shaded-pole and EC motors, it can be seen that utilities would be required to supply $80 \%$ less apparent power and $80 \%$ less current for Q-Sync motors than for the baseline combination of shaded-pole and EC motors. This would amount to significant savings for the utilities.

This paper has focused on evaporator fan motors for commercial refrigeration equipment and beverage vending machines. However, there are other applications where similar results could be achieved, such as evaporator and condenser fans in domestic refrigerators/freezers; walk-in coolers/freezers; and commercial and residential heating, ventilating, and air-conditioning systems. The installed base of fan motors in these applications collectively numbers in the hundreds of millions. As shown in Table 5, DOE BTO estimates that the annual source energy consumption of these fans is approximately 2.3 quads (NCI 2013). Thus these applications consume significantly more electricity than the 9-12 W motors that are the subject of this report-nearly 30 times as much source energy. Therefore, it is possible that a broader upgrade to Q-Sync fan motors could reduce source energy consumption by as much as one quad or more, with proportional environmental benefits. 
Table 5. Annual source energy consumption of fans in residential and commercial buildings (NCI 2013)

\begin{tabular}{lc}
\hline Fan application & $\begin{array}{c}\text { Primary energy } \mathbf{( 1 0}^{\mathbf{1 2}} \\
\text { Btu/year) }\end{array}$ \\
\hline Residential Buildings & \\
CAC/HP outdoor fan & 227.2 \\
Furnace fan & 442.9 \\
RAC condenser fan & 16.4 \\
Dehumidifier condenser fan & 8.6 \\
Refrigerator/freezer condenser fan & 46.5 \\
Refrigerator/freezer evaporator fan & 39.2 \\
Commercial Buildings & \\
PTAC indoor fan & 11.9 \\
PTAC outdoor fan & 7.9 \\
SPVAC indoor fan & 1.8 \\
SPVAC outdoor fan & 1.2 \\
CUAC indoor fan-small & 86.0 \\
CUAC indoor fan-medium & 47.9 \\
CUAC indoor fan-large & 11.2 \\
CUAC outdoor fan-small & 86.0 \\
CUAC outdoor fan-medium & 47.9 \\
CUAC outdoor fan-large & 11.2 \\
Exhaust fan & 468.6 \\
Room fan coil & 9.7 \\
AHU & 492.6 \\
Cooling tower fan & 37.9 \\
CRE condenser fan & 37.7 \\
BVM condenser fan & 60.2 \\
WICF condenser fan & 39.9 \\
WICF evaporator fan & 39.9 \\
ACIM condenser fan & 11.8 \\
Total: & $\mathbf{2 2 9 2 . 1}$ \\
\hline
\end{tabular}

$\mathrm{CAC}=$ central air conditioner $\mathrm{HP}=$ heat pump $\mathrm{RAC}=$ room air conditioner PTAC $=$ packaged terminal air conditioner; SPVAC = single packaged vertical air conditioner; CUAC = commercial unitary air conditioner; $\mathrm{AHU}=$ air-handling unit; $\mathrm{CRE}=$ commercial refrigeration equipment; $\mathrm{BVM}=$ beverage vending machine; $\mathrm{WICF}=$ walk-in cooler/freezer; $\mathrm{AICM}=$ automatic commercial ice maker 


\section{REFERENCES}

de Almeida, A., and S. Greenberg. 2004. "Electric Motors.” In Encyclopedia of Energy. Elsevier Academic Press, San Diego, California.

Deru, M., and P. Torcellini. 2007. Source Energy and Emission Factors for Energy Use in Buildings. NREL/TP-550-38617, National Renewable Energy Laboratory, Golden, Colorado.

DOE (Department of Energy). 2011. 2010 Buildings Energy Data Book. Office of Energy Efficiency and Renewable Energy, US Department of Energy, Washington, D.C.

EIA (Energy Information Administration). 2015. "Electric Power Monthly with Data for March 2015." US Department of Energy, Washington, D.C., May.

Flynn, C. J., and C. N. Tracy. 2014. "Divided Phase AC Synchronous Motor Controller." US Patent Application US 2014/0152228 A1, June 5.

Hughes, A., and B. Drury. 2013. Electric Motors and Drives-Fundamentals, Types and Applications. 4th Edition. Elsevier, Oxford.

IBIS World. 2015. "Bars and Nightclubs in the US: Market Research Report." Accessed July 15, 2015. http://www.ibisworld.com/industry/default.aspx?indid=1685.

NACS (Association for Convenience and Fuel Retailing). 2015. "U.S. Convenience Store Count." Accessed July 15, 2015.

http://www.nacsonline.com/research/factsheets/scopeofindustry/pages/industrystorecount.aspx.

NCI (Navigant Consulting Inc.) and PNNL (Pacific Northwest National Laboratory). 2011. Preliminary Technical Support Document (TSD): Energy Conservation Program for Certain Commercial and Industrial Equipment: Commercial Refrigeration Equipment. Appliances and Commercial Equipment Standards, Building Technologies Program, Office of Energy Efficiency and Renewable Energy, US Department of Energy, Washington, D.C.

NCI (Navigant Consulting Inc.). 2013. Energy Savings Potential and Opportunities for High-Efficiency Electric Motors in Residential and Commercial Equipment. Building Technologies Program, Office of Energy Efficient and Renewable Energy, US Department of Energy, Washington, D.C.

NRA (National Restaurant Association). 2015. "Facts at a Glance." Accessed July 15, 2015. http://www.restaurant.org/News-Research/Research/Facts-at-a-Glance.

Progressive Grocer. 2015. 82nd Annual Report of the Grocery Industry.

Statistic Brain Research Institute. 2015. "Vending Machine Industry Statistics.” Accessed July 15, 2015. http://www.statisticbrain.com/vending-machine-industry-statistics/.

Wilson, T. G., and P. H. Trickey. 1962. "D-C Machine with Solid-State Commutation.” AIEE paper CP62-1372, presented at the AIEE Fall General Meeting, Chicago, IL, October 7-12. 